\title{
Perinatal transmission of SARS-CoV-2 and transfer of maternal IgG/neutralizing anti-SARS-CoV-2 antibodies from mothers with asymptomatic infection during pregnancy
}

\author{
Nandini Malshe ${ }^{1}$ - Suprabha K. Patnaik ${ }^{1}$ - Sanjay Lalwani ${ }^{2} \cdot$ Pradeep Suryawanshi $^{1} \cdot$ Ruta Kulkarni $^{3} \cdot$ Suhas Mhaske $^{3}$. \\ Akhilesh Chandra Mishra ${ }^{3}$. Vidya Arankalle ${ }^{3}$
}

Received: 7 May 2021 / Accepted: 22 June 2021 / Published online: 7 July 2021

(c) Springer-Verlag GmbH Germany, part of Springer Nature 2021

\begin{abstract}
Purpose COVID-19 pandemic remains a serious public health threat worldwide. In view of the limited data on the risk of perinatal transmission of SARS-CoV-2 and transfer of maternal anti-SARS-CoV-2 antibodies, the present study was undertaken.

Methods A prospective study including 57 pregnant women with a positive SARS-CoV-2 RNA test (SARS-CoV-2-RNA+) and 59 neonates born to them was conducted at Pune, India. 39 viral RNA negative (SARS-CoV-2-RNA-negative) pregnant women and their 39 neonates were included as controls. Neonatal nasal swab/cord blood samples were subjected to SARSCoV-2 RNA detection by RT-PCR for investigation of perinatal transmission. Transfer of maternal antibodies was studied using ELISA and PRNT.

Results 10/57 SARS-CoV-2-RNA+ mothers were symptomatic. The duration between COVID-19 diagnosis and delivery was $\leq 7$ days for $82.4 \%$. Perinatal transmission as evidenced by viral RNA in the neonatal nasal swab/cord blood (CB) was $3.6 \%$. IgG-anti-SARS-CoV-2 positivity was $21.6 \%$. Of the 39 neonates born to SARS-CoV-2-RNA-negative mothers, 20 $(51 \%)$ and none, respectively, were positive for IgG-anti-SARS-CoV-2 and viral RNA. Preterm deliveries were higher in SARS-CoV-2-RNA+ $(18.6 \%)$ than SARS-CoV-2 RNA-negative $(0 / 39)$ mothers $(p<0.005)$. Respiratory distress at birth $(<4 \mathrm{~h})$ was higher among neonates of SARS-CoV-2-RNA+ $(20 / 59,33.9 \%)$ than SARS-CoV-2-RNA-negative mothers $(3 / 39$, $7.7 \% ; p<0.001$ ). 75\% IgG-positives exhibited neutralization potential with mean PRNT titers of $42.4 \pm 24$ (SARS-CoV-2RNA+) and $72.3 \pm 46.7$ (SARS-CoV-2 RNA-negative); higher in the latter $(p<0.05)$.

Conclusion The rate of perinatal transmission was low. Transfer of maternal antibodies was lower among SARS-CoV-2RNA+ mothers than SARS-CoV-2-RNA-negative mothers with subclinical infection during pregnancy. Presence of neutralizing antibodies in majority of IgG-positives suggests protection from SARS-CoV-2 in early life.
\end{abstract}

Keywords SARS-CoV-2 $\cdot$ COVID-19 $\cdot$ Perinatal transmission $\cdot$ Neutralizing antibodies $\cdot$ Pregnant women $\cdot$ India

Vidya Arankalle

varankalle@yahoo.com

1 Department of Neonatology, Medical College, Bharati Vidyapeeth (Deemed To Be University), Pune, Maharashtra, India

2 Department of Pediatrics, Medical College, Bharati Vidyapeeth (Deemed To Be University), Pune, Maharashtra, India

3 Interactive Research School for Health Affairs, Bharati Vidyapeeth (Deemed To Be University), Pune-Satara Road, Katraj-Dhankawadi, Pune, Maharashtra 411043, India

\section{Introduction}

COVID-19 pandemic has entered in the second year and continues to affect global population and economies. In view of the importance, SARS-CoV-2 infections among pregnant women and the possibility of vertical/perinatal transmission was examined early during the pandemic [1]. Overall, COVID-19 in infants was found to be a rare disease, though, serious consequences were observed, once infected [2-5].

Maternal antibodies provide much required protection of neonates against various infectious agents including viruses. Data in relation to the maternal transfer of anti-SARS-CoV-2 antibodies are scanty and needs to be urgently generated in 
different populations. Transfer of maternal antibodies is a function of corresponding antibody titers in the mothers at the time of delivery. It is well recognized that COVID-19 patients with severe disease develop early and higher titers of $\operatorname{IgG}$ and neutralizing antibodies [6-9, our unpublished observations]. Whether dynamics of anti-SARS-CoV-2 antibodies in pregnant women is influenced by pregnancy associated immunomodulation is not yet clear.

The first COVID-19 case in India was diagnosed on 30th January 2020 while the first case in Pune wherein this study was carried out was identified on 19th March 2020. In view of the importance of understanding the risk of perinatal transmission of SARS-CoV-2, a study was initiated in June 2020 when $\sim 8000$ cases/week were reported and concluded at the end of September with 82,867 cases/week. We estimated the risk of perinatal transmission, IgG-anti-SARS$\mathrm{CoV}-2$ antibody positivity in the neonates and neutralizing antibody titers among the antibody positives.

\section{Materials and methods}

\section{Study population and clinical specimens}

This prospective cohort study was conducted during June-September 2020 at Bharati Vidyapeeth (Deemed to be University) hospital, a tertiary care hospital at Pune, a Metropolitan city in western India. Because of the stateof-art facilities and a 60-bedded neonatal ICU, the hospital caters to a large number of high-risk pregnancies. The controls were recruited in the month of December 2020. The study was approved by the Human Ethics Committee of the hospital.

A total of 57 pregnant women who tested positive for SARS-CoV-2 RNA within 0-3 weeks before delivery at the hospital and consented for participation were included in the study. Neonates $(n=59)$ of these women were separated immediately after birth and received mother's pumped breastmilk whenever possible. Respiratory distress was monitored in the neonates, defined as respiratory rate $>60$ per minute (counting for $1 \mathrm{~min}$ ) accompanied by subcostal or intercostal retractions. After initial follow-up of 2 days at the hospital, telephonic follow-up was done till 30 days of age. Nasopharyngeal swabs (NPS) $(n=56)$ and umbilical cord blood (CB) samples $(n=51)$ were obtained from these neonates within a day of birth. CB was available for the neonate from whom NPS could not be collected. In addition, two mothers with symptomatic disease 2 months prior to delivery, and 39 pregnant women without a positive PCR test (control mothers) were also studied. NPS specimens were not collected while CB samples $(n=39)$ were collected from the neonates born to control mothers. Blood samples could be collected from 9 mothers with confirmed
COVID-19 while blood samples were not collected from the control mothers.

\section{Serology}

For the detection of $\operatorname{IgG}$ and $\operatorname{IgM}$ antibodies, SCoV-2 Detect IgG ELISA and SCoV-2 Detect IgM ELISA were used (Inbios IgG ELISA, Inbios International, Inc., USA). The presence and titers of anti-SARS-CoV-2 neutralizing antibodies were determined using plaque reduction neutralization test (PRNT) as per the protocol described earlier [8].

\section{SARS-CoV-2 RNA detection}

Extraction of viral RNA from neonatal NPS or CB was conducted using QIAamp viral RNA extraction kit (Qiagen, Germany) and screening for SARS-CoV-2 RNA was performed by Real time PCR (PathoDetect Covid-19 Test Kit, Mylab Discovery, India) as per the manufacturer's protocol.

\section{Results}

From June-September 2020, 345 women delivered at the hospital giving birth to 347 babies. Among these, SARSCoV-2 RNA positivity could be detected in the NPS specimens from 58 mothers (16.7\%). One neonate born by lower segment cesarean section (LSCS) to one COVID-19 positive mother with HELLP syndrome died of perinatal asphyxia, was not tested for the virus and excluded from analysis. Fifty-nine neonates born to the remaining 57 mothers were included in this study and completed full follow-up till 30 days of age. All the neonates were separated from their mothers immediately after birth as none of the parents were willing for rooming-in. Majority of the babies (58/59; 98\%) were discharged from the hospital after 2 days of delivery. Two neonates born to mothers with symptomatic COVID19, 60 days before delivery were also included to understand transfer of maternal antibodies. During this time, recruitment of SARS-CoV-2 negative mothers was not possible and hence when the cases in Pune showed a downward trend in December, 39 pregnant women negative for SARS-CoV-2 RNA within one week of delivery were included as controls. NPS was not collected from the neonates of these mothers. None of these women gave history of (H/O) COVID-19 or related symptoms during pregnancy.

\section{Participant characteristics}

Table 1 provides details of the participants. The study included 96 pregnant women with $(n=57)$ or without ( $n=39$, controls) SARS-CoV-2 RNA positivity at $/<3$ weeks before delivery. Among the patient group, 10 (17.5\%) were 
Table 1 Characteristics of the study population

\begin{tabular}{|c|c|c|}
\hline Parameter & SARS-CoV-2 RNA positives & $\begin{array}{l}\text { SARS-CoV-2 } \\
\text { RNA negatives }\end{array}$ \\
\hline Duration of recruitment & June-September 2020 & December 2020 \\
\hline \multicolumn{3}{|l|}{ Mothers: } \\
\hline Number of mothers & 57 & 39 \\
\hline Age (years, mean \pm SD) & $28.1 \pm 4.9$ & $27.4 \pm 4.1$ \\
\hline COVID-19 symptoms at delivery & $10(17.5 \%)$ & 0 \\
\hline Type of delivery-LSCS & $44(77.2 \%)$ & $33(84.6 \%)$ \\
\hline Type of delivery-vaginal & 13 & 3 \\
\hline Type of delivery-instrument assisted & 2 & 0 \\
\hline \multicolumn{3}{|l|}{ Neonates: } \\
\hline No of neonates & 59 & 39 \\
\hline Preterm birth & $11(18.6 \%)$ & 0 \\
\hline Gestational age (weeks, mean $\pm \mathrm{SD}$ ) & $37.5 \pm 2.1$ & $38.3 \pm 1.6$ \\
\hline Birth weight (grams, mean \pm SD) & $2699 \pm 530$ & $2995 \pm 92$ \\
\hline Respiratory distress at birth & $20(33.9 \%)$ & $3(7.7 \%)$ \\
\hline
\end{tabular}

LSCS lower segment cesarean section symptomatic with fever $(n=6)$, breathlessness $(n=2)$, sore throat $(n=2)$, cough $(n=1)$ and diarrhea $(n=1)$. One of these patients required admission in the intensive care unit, recovered and was discharged. Of note, 47/57 (82.4\%) infections in the pregnant women were asymptomatic, the ratio of symptomatic: asymptomatic infections being 1:4.7. Thus, though immunocompromised, a large proportion of pregnant women do develop asymptomatic infection.

Of the 59 neonates born to SARS-CoV-2-RNA positive mothers, $11(18.6 \%)$ were preterm while all the SARS-CoV-2 RNA negative women delivered full term $(p<0.005)$ (Table 1, Fig. 1). Preterm deliveries among symptomatic mothers $(6 / 10,60 \%)$ were significantly higher than those with asymptomatic infection $(5 / 47$, $10.6 \%, p<0.001)$. The mother requiring hospitalization in an ICU delivered full term. No differences in the proportion of preterm deliveries were found when primigravida $(5 / 27,18.5 \%)$ and multigravida mothers $(4 / 25,16 \%)$ were compared $(p>0.1)$. For 5 mothers, the gravida data were not available. Twelve neonates required respiratory support; meconium aspiration $(n=3)$, transient tachypnea (8) and pneumonia (1). Prolonged respiratory support was required for one neonate with Schwartz Jampel syndrome and not for COVID-19. Importantly, respiratory distress at delivery that lasted for $<4 \mathrm{~h}$, was higher among neonates born to mothers with SARS-CoV-2 RNA (20/59, 33.9\%)
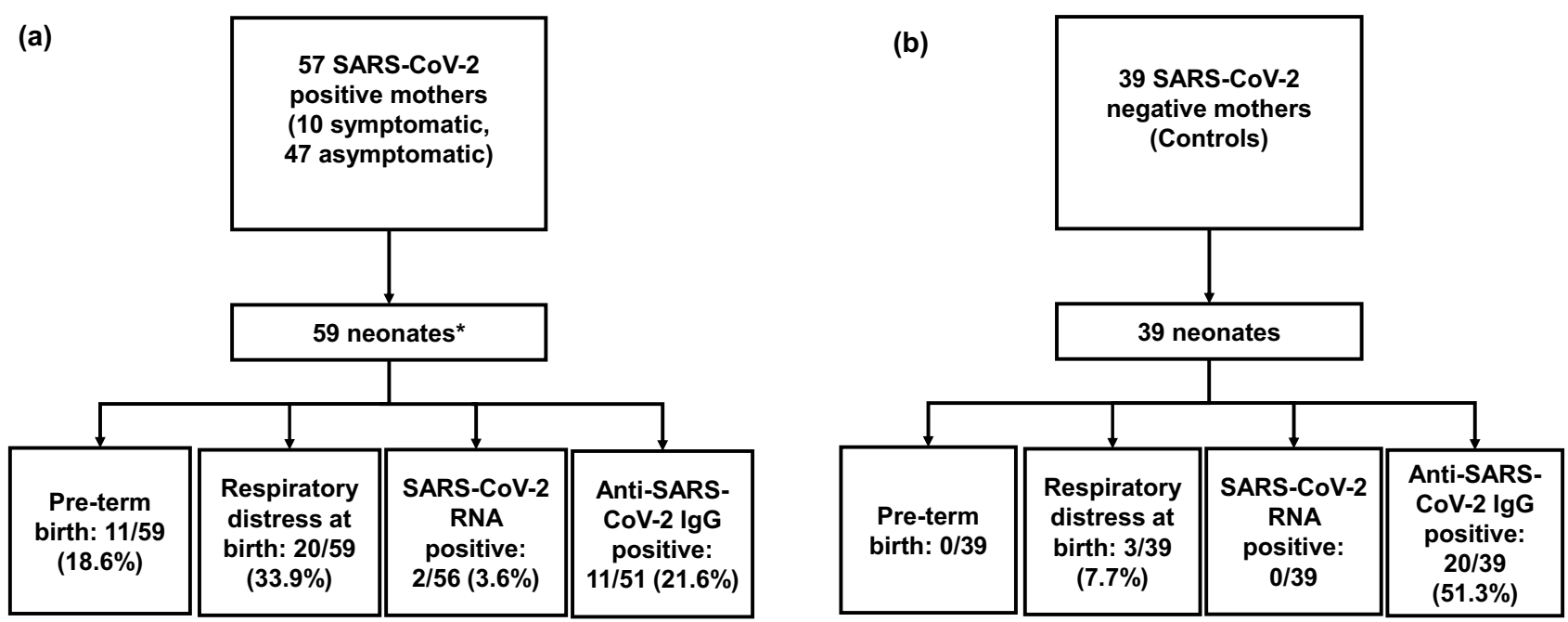

*Includes 2 pairs of twins

Fig. 1 Summary of clinical characteristics and laboratory investigations for neonates born to SARS-CoV-2 positive (a) and negative (b) mothers 
than the control mothers $(3 / 39,7.7 \% ; p<0.001)$ (Table 1 ; Fig. 1).

\section{SARS-CoV-2 RNA and IgG/neutralizing anti-SARS-CoV-2 antibodies in the neonates}

Majority of the pregnant women $(36 / 57,63.1 \%)$ were screened for viral RNA within 3 days of delivery while 47/57 (82.4\%) were within 7 days of childbirth (Table 2). SARS-CoV-2 RNA was detected in 1/56 (1.8\%) NPS and $1 / 51$ (1.9\%) CB specimens obtained from the neonates born to SARS-CoV-2 RNA positive mothers. These neonates were born 9 days and 2 days, respectively after the mother's COVID-19 diagnosis. Both the neonates showing viral RNA positivity were born to symptomatic mothers. Overall, the risk of perinatal transmission was $3.6 \%(2 / 56)$. All the 39 CB samples collected from the control mothers were viral RNA negative (Fig. 1.).

IgG-anti-SARS-CoV-2 positivity among neonates born to SARS-CoV-2 RNA positive mothers was $21.6 \%$ (11/51, Table 2) suggestive of lack/lower levels of antibodies in majority of these mothers. Of the $9 \mathrm{IgG}$ positives subjected to PRNT, 2 with OD values $<0.8$ were negative, while the remaining were positive, with mean $\mathrm{PRNT}_{50}$ titer being $42.4 \pm 24$. Both the neonates born to mothers with COVID19 disease 60 days prior to delivery were positive for both IgG and neutralizing antibodies (Tables 2, 3). Surprisingly, very high proportion of neonates born to the control mothers were positive for IgG-anti-SARS-CoV-2 antibodies $(20 / 39,51.3 \%, p<0.005)$ revealing prevalent asymptomatic infection. Since the first case of COVID-19 in Pune, India was detected on 29th March 2020, all these women were infected during pregnancy. Of the 20 ELISA positives, 15 showed presence of neutralizing antibodies (Nabs) with mean PRNT $_{50}$ titer $72.3 \pm 46.7$. Five samples showing low OD values in ELISA $(4<0.7$ and one 1.53$)$ were negative for neutralizing antibodies $\left(\mathrm{PRNT}_{50}<10\right)$. One sample with OD of 1.1 did show Nabs at a titer of 19 .

\section{Antibody patterns among mother-infant pairs}

We could study nine mother-infant pairs (Table 3 ). Of these, four mothers delivering after 1-5 days of COVID-19 diagnosis and their neonates were negative in ELISA and PRNT. Four mothers were positive in both ELISA and PRNT. Of these, three women with symptomatic infection 17 days, 2 months and 2 months before delivery were circulating neutralizing antibodies and transferred these antibodies to the neonates; the ratio of antibody titers in the mothers and neonates were: $0.07,0.3$ and 0.27 . The neonate of the fourth mother (ELISA+, PRNT+) with neutralizing antibody titer of 106 was IgG-positive but lacked neutralizing antibodies. One mother was IgG-positive but lacked neutralizing antibodies (ELISA+, PRNT-), and the neonate of this mother was antibody-negative. Four of the mothers were IgM positive while their neonates lacked these antibodies.

\section{Discussion}

Our study confirms earlier reports of lower risk of perinatal transmission of SARS-CoV-2 [1]. We and others [10] demonstrate that SARS-CoV-2 infection during the third trimester is predominantly asymptomatic. Immunomodulation to protect fetus during entire pregnancy enhances susceptibility of a pregnant woman to various pathogens. Despite this immunocompromised condition, a large proportion of pregnant women do develop asymptomatic infection; in our series, asymptomatic infections were 4.7-fold higher than the symptomatic disease. In the same setting, the ratio of subclinical and clinical SARSCoV-2 infection was estimated to be 1:7.8 in males and

Table 2 Relationship of duration between COVID-19 diagnosis and delivery with the detection of SARS-CoV-2 RNA and IgG-anti-SARS$\mathrm{CoV}-2$ antibodies in the cord blood samples

\begin{tabular}{|c|c|c|c|c|}
\hline \multicolumn{2}{|l|}{ Mothers } & \multicolumn{3}{|l|}{ Infants } \\
\hline \multirow[t]{2}{*}{$\begin{array}{l}\text { Duration between viral RNA detection and } \\
\text { delivery (No. of days) }^{\mathrm{a}}\end{array}$} & \multirow[t]{2}{*}{$\begin{array}{l}\text { No. of SARS-CoV-2 } \\
\text { RNA positives }\end{array}$} & \multicolumn{2}{|c|}{$\begin{array}{l}\text { SARS-CoV-2 RNA } \\
\text { No. positive/No. tested (\%) }\end{array}$} & \multirow{2}{*}{$\begin{array}{l}\text { IgG-anti-SARS- } \\
\text { CoV-2 antibod- } \\
\text { ies } \\
\text { No. positive/no. } \\
\text { tested }(\%)\end{array}$} \\
\hline & & Nasopharyngeal swab & Cord blood & \\
\hline $0-3$ & 36 & $0 / 36$ & $1 / 34(2.9)$ & $8 / 34(23.5)$ \\
\hline $4-7$ & 11 & $0 / 10$ & $0 / 8$ & $1 / 8$ \\
\hline $8-14$ & 06 & $1 / 6$ & $0 / 6$ & $0 / 6$ \\
\hline $15-21$ & 04 & $0 / 4$ & $0 / 3$ & $2 / 3$ \\
\hline Total & 57 & $1 / 56(1.8)$ & 1/51 (1.9) & $11 / 51(21.6)$ \\
\hline RNA negative at delivery (controls) & 0 & Not tested & $0 / 39$ & $20 / 39(51.3)$ \\
\hline
\end{tabular}

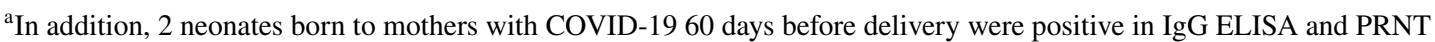




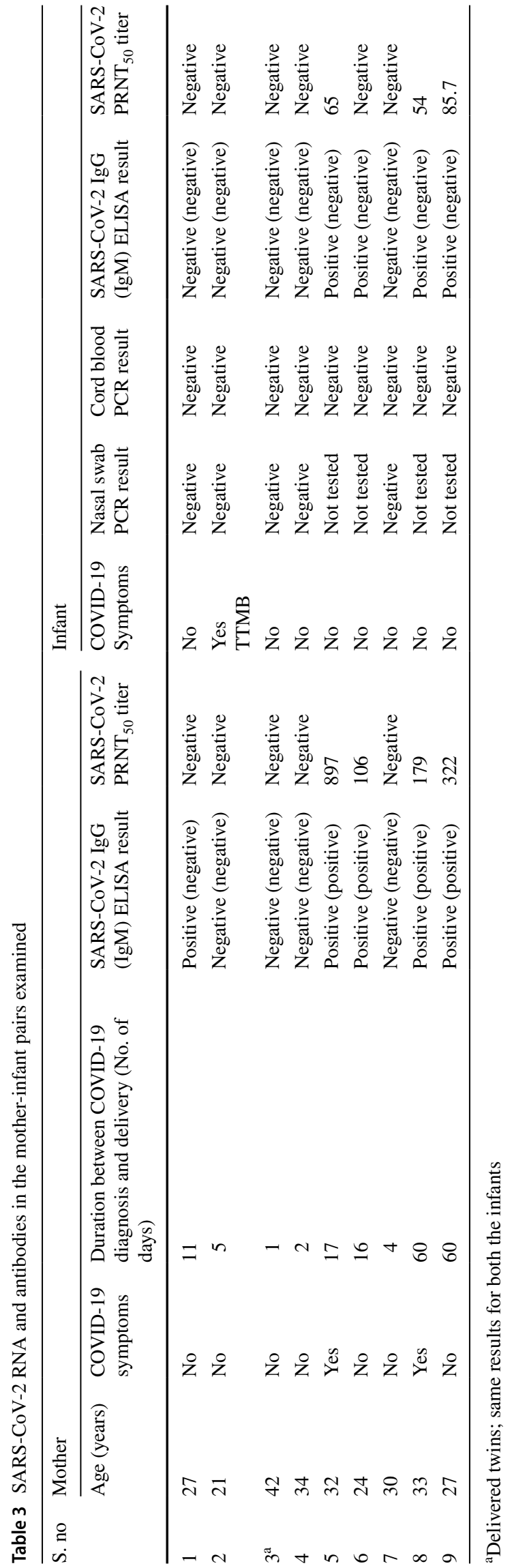

1:1 in non-pregnant females when 82 male and 27 female patients were studied [9]. Though significant, the differential clinical presentations in pregnant and non-pregnant women need to be confirmed in a larger cohort. In hepatitis $\mathrm{E}$, a viral disease with high mortality in pregnant women, the ratio of clinical and subclinical infections in the later trimesters was found to be 1:13 [11]. For majority of the pregnant women, duration between COVID-19 diagnosis and delivery was $<3(36 / 57,63.1 \%)$ or $<7(47 / 57,82.4 \%)$ days. Perinatal transmission was evident in one neonate born on 2nd day (CB positivity) and another born on day 9 (NPS positivity) post-diagnosis $(2 / 56,3.6 \%)$. Of note, both the mothers were symptomatic and the babies did not develop symptoms and could be diagnosed only because of the presence of viral RNA.

Two important observations emerged from this study. First, the proportion of preterm deliveries was higher in the mothers with SARS-CoV-2 infection than the control mothers without viral RNA at the time of delivery $(p<0.005)$. Significant association of clinical disease with higher preterm deliveries $(6 / 10,60 \%, p<0.001)$ is noteworthy. A recent study reported two to threefold increase in the risk of preterm birth among women with symptomatic COVID-19 [12]. This was mainly attributed to medical recommendation to deliver early to improve maternal oxygenation [13]. The influence of clinical presentations on preterm delivery needs to be carefully analyzed. Second, $\sim 34 \%$ babies born to infected mothers developed respiratory distress for $<4 \mathrm{~h}$ as against $7.7 \%$ among those born to the control mothers. Indepth studies with larger cohorts are required to confirm this observation and understand basis for the observed respiratory distress. For women with symptomatic SARS-CoV-2 in the third trimester, a modest but significantly increased risk of preterm delivery and intrapartum stress was recorded in Italy [10]. Of the estimated 14.9 million preterm infants born every year globally, India contributes to $>3.5$ million with $13 \%$ annual preterm births [14]. In view of the long-term effects of preterm birth, it would be necessary to protect pregnant women from SARS-CoV-2 infection. Pregnant women were not included in the clinical trials of COVID-19 vaccines. However, it is heartening to note that administration of mRNA vaccines to 84 pregnant women led to robust humoral immunity that was comparable to non-pregnant counterparts [15].

While writing this manuscript, an online version of a large study conducted employing National Neonatology Forum (NNF) of India registry, wherein various hospitals voluntarily provide information became available [16]. Based on viral RNA positivity in the NPS specimens, perinatal transmission was reported in $106(8 \%)$ and horizontal transmission in 21 (1.5\%) neonates. Amongst symptomatic neonates, most morbidities were related to prematurity and perinatal events. 
Another important issue is the transfer of maternal antibodies that can protect the infants from SARS-CoV-2 infection. Our data revealed that when the duration between infection and delivery was $<1$ week, the transfer of maternal antibodies was less frequent (21.4\%, Table 2). Unfortunately, we could collect blood samples from only four mothers in this category (Table 3 ) and all were antibody negative. It seems that most infants born to mothers early during disease will remain susceptible to SARS-CoV-2 infection. However, if the duration is $2-3$ weeks $(n=3)$ or more ( 60 days, $n=2)$, $\mathrm{IgG}$ and neutralizing antibodies are transferred (Table 2). The absence of IgM in all the 4 samples tested is indicative of lack of active SARS-CoV-2 infection in these neonates. Transfer of vaccine-induced antibodies has also been recently reported [15].

Our study included 39 pregnant women with negative RT-PCR test and without history of COVID-19 as controls for perinatal transmission. However, serologic testing of CB samples revealed widespread asymptomatic SARS-CoV-2 infection in these women earlier during pregnancy and extensive transfer of maternal antibodies $(51.3 \%$ IgG positivity). Of note, neutralizing antibodies were present in $75 \%$ of these ELISA positives (15/20) and their $\mathrm{PRNT}_{50}$ titers were higher than those among the neonates born to mothers within 3 weeks of COVID-19 diagnosis $(p<0.05)$, although the number of samples in the latter group was small. Clearly, SARS-CoV-2 infection was highly prevalent in this population leading to effective transfer of neutralizing antibodies to the neonates. It seems that majority of these women were infected much earlier before delivery and hence an efficient transfer of antibodies was possible. Taken together, with increased number of infections with substantial subclinical presentation in Pune population, a significant proportion of neonates may have neutralizing maternal antibodies. Currently correlates of protection are not known for SARSCoV-2. In the absence of data on the persistence of these antibodies, one would expect at least short-term protection against the infection. So far, maternal transfer of neutralizing antibodies has not been reported.

A recent study based on 22 mother-cord pairs from USA documented inefficient transfer of maternal SARSCoV-2-specific antibodies when compared to influenza and pertussis [17]. ELISA was used for antibody quantitation. Our study confirms this observation and extends to neutralizing antibodies, though we could study only 5 antibody positive mother-cord pairs (Table 3 ). A reduction of 3.3-13.8-fold was recorded. Transfer was evident when maternal Nab titers were $>100$. A larger cohort needs to be studied to verify this observation.

COVID-19 remains a rare disease among infants. Children were usually spared when the original Wuhan strain was prevalent [2-5]. When the present study was conducted, original SARS-CoV-2 was prevalent $[18,19]$. During the current second wave, increased infections among pediatric population are being reported and mutant viruses are predominant [20-23, our unpublished observations]. It would be necessary to examine the effect of the mutated viruses on neonate COVID-19.

In conclusion, our results confirm increased preterm deliveries in SARS-CoV-2 infection, clinical disease favoring this outcome. Further, perinatal SARS-CoV-2 transmission was $3.6 \%$ with only $21.6 \%$ neonates receiving maternal antibodies. Predominant asymptomatic SARS-CoV-2 infection during pregnancy led to effective transfer of antibodies in $51 \%$ neonates. $75 \%$ of the IgG positives exhibited neutralizing potential suggestive of protection in early life.

Acknowledgements The authors are indebted to the participating parents. Excellent technical assistance by Ms Prajakta Rane, Mr Pravin Kore in PRNT assays, Mr Shambhu Pisal for RT-PCR and Mr Tushar Bhosale in sample collection are gratefully acknowledged.

Funding This work was supported by a grant from Department of Biotechnology-Biotechnology Industry Research Assistance Council (DBT-BIRAC), India, under the "Innovate in India (i3)" program of National Biopharma Mission (Grant No. BIRAC/BT/NBM0095/02/18).

\section{Declarations}

Conflict of interest All authors declare that they have no conflict of interest.

\section{References}

1. Chi J, Gong W, Gao Q. Clinical characteristics and outcomes of pregnant women with COVID-19 and the risk of vertical transmission: a systematic review. Arch Gynecol Obstet. 2021;303:337-45.

2. Dong $\mathrm{Y}$, Mo X, Hu Y, Qi X, Jiang F, Jiang Z, Tong S. Epidemiology of COVID-19 among children in China. Pediatics. 2020;145:e20200702.

3. Liguoro I, Pilotto C, Bonanni M, Ferrari ME, Pusiol A, Nocerino A, Vidal E, Cogo P. SARS-COV-2 infection in children and newborns: a systematic review. Eur J Pediatr. 2020;179:1029-46.

4. Mithal LB, Machut KZ, Muller WJ, Kociolek LK. SARSCoV-2 infection in infants less than 90 Days Old. J Pediatr. 2020;224:150-2.

5. Ovalı F. SARS-CoV-2 infection and the newborn. Front Pediatr. 2020;8:294

6. Kulkarni R, Patil HP, Palkar S, Lalwani S, Mishra AC, Arankalle V. Anti-SARS-CoV-2 IgG antibody response among Indian COVID-19 patients using $\beta$-propiolactone-inactivated, whole virus-based indirect ELISA. J Virol Methods. 2021;287:113996.

7. Liu L, To KK, Chan KH, Wong YC, Zhou R, Kwan KY, Fong CH, Chen LL, Choi CY, Lu L, Tsang OT, Leung WS, To WK, Hung IF, Yuen KY, Chen Z. High neutralizing antibody titer in intensive care unit patients with COVID-19. Emerg Microbes Infect. 2020;9(1):1664-70.

8. Patil HP, Rane PS, Shrivastava S, Palkar S, Lalwani S, Mishra AC, Arankalle VA. Antibody (IgA, IgG, and IgG Subtype) responses to SARS-CoV-2 in severe and nonsevere COVID-19 Patients. Viral Immunol. 2021;34(3):201-9. 
9. Shrivastava S, Palkar S, Shah J, Rane P, Lalwani S, Mishra AC, Arankalle VA. Early and high SARS-CoV-2 neutralizing antibodies are associated with severity in COVID-19 patients from India. Am J Trop Med Hyg. 2021:tpmd210014.

10. Crovetto F, Crispi F, Llurba E, Pascal R, Larroya M, Trilla C, Camacho M, Medina C, Dobaño C, Gomez-Roig MD, Figueras F, Gratacos E; KidsCorona Pregnancy COVID-19 group. Impact of SARS-CoV-2 infection on pregnancy outcomes: a populationbased study. Clin Infect Dis. 2021:ciab104.

11. Arankalle VA, Chadha MS, Dama BM, Tsarev SA, Purcell RH, Banerjee K. Role of immune serum globulins in pregnant women during an epidemic of hepatitis E. J Viral Hepat. 1998;5:199-204.

12. Vousden N, Bunch K, Morris E, Simpson N, Gale C, O’Brien P, Quigley M, Brocklehurst P, Kurinczuk JJ, Knight M. The incidence, characteristics and outcomes of pregnant women hospitalized with symptomatic and asymptomatic SARS-CoV-2 infection in the UK from March to September 2020: a national cohort study using the UK Obstetric Surveillance System (UKOSS). PLoS One. 2021;16(5):e0251123.

13. Preterm labour and birth. NICE Guideline 25. 2021. https://www. nice.org.uk/guidance/ng25/evidence/full-guideline-pdf-21768 38029. Accessed 15 Jun 2021.

14. Healthy Newborn Network-India. 2021. https://www.healthynew bornnetwork.org/country/india/. Accessed 1 May 2021.

15. Gray KJ, Bordt EA, Atyeo C, Deriso E, Akinwunmi B, Young N, Baez AM, Shook LL, Cvrk D, James K, De Guzman R, Brigida S, Diouf K, Goldfarb I, Bebell LM, Yonker LM, Fasano A, Rabi SA, Elovitz MA, Alter G, Edlow AG. Coronavirus disease 2019 vaccine response in pregnant and lactating women: a cohort study. Am J Obstet Gynecol. 2021:S0002-9378(21)00187-3.

16. National Neonatology Forum (NNF) Covid-19 Registry Group. Outcomes of Neonates Born to Mothers with Coronavirus Disease 2019 (COVID-19) - National Neonatology Forum (NNF) India COVID-19 Registry. In: Indian paediatrics. March 2021. 2021. https://www.indianpediatrics.net/COVID29.03.2020/RP-00300. pdf. Accessed 26 Apr 2021.

17. Atyeo C, Pullen KM, Bordt EA, Fischinger S, Burke J, Michell A, Slein MD, Loos C, Shook LL, Boatin AA, Yockey LJ, Pepin D, Meinsohn MC, Nguyen NMP, Chauvin M, Roberts D, Goldfarb IT, Matute JD, James KE, Yonker LM, Bebell LM, Kaimal AJ, Gray KJ, Lauffenburger D, Edlow AG, Alter G. Compromised SARS-CoV-2-specific placental antibody transfer. Cell. 2021;184:628-42.

18. Potdar V, Cherian SS, Deshpande GR, Ullas PT, Yadav PD, Choudhary ML, Gughe R, Vipat V, Jadhav S, Patil S, Nyayanit
D, Majumdar T, Walimbe A, Gaikwad S, Dighe H, Shete-Aich A, Mohandas S, Chowdhury D, Sapkal G, Basu A, Gupta N, Gangakhedkar RR, Giri S, Dar L, Jain A, Malhotra B, Abraham P. National Influenza Centre (NIC) Team: Genomic analysis of SARS-CoV-2 strains among Indians returning from Italy, Iran \& China, \& Italian tourists in India. Indian J Med Res. 2020;151:255-60.

19. Shrivastava S, Patil HP, Mhaske ST, Palkar S, Lalwani S, Mishra AC, Arankalle VA. Isolation and genetic characterization of SARS-CoV-2 from Indian patients in a single family without $\mathrm{H} / \mathrm{O}$ travel abroad. Virus Genes. 2021;57(3):245-9.

20. Kirby T. New variant of SARS-CoV-2 in UK causes surge of COVID-19. Lancet Respir Med. 2021;9:e20-1.

21. Tegally H, Wilkinson E, Giovanetti M, Iranzadeh A, Fonseca V, Giandhari J, Doolabh D, Pillay S, San EJ, Msomi N, Mlisana K, von Gottberg A, Walaza S, Allam M, Ismail A, Mohale T, Glass AJ, Engelbrecht S, Van Zyl G, Preiser W, Petruccione F, Sigal A, Hardie D, Marais G, Hsiao NY, Korsman S, Davies MA, Tyers L, Mudau I, York D, Maslo C, Goedhals D, Abrahams S, Laguda-Akingba O, Alisoltani-Dehkordi A, Godzik A, Wibmer CK, Sewell BT, Lourenço J, Alcantara LCJ, Kosakovsky Pond SL, Weaver S, Martin D, Lessells RJ, Bhiman JN, Williamson C, de Oliveira T. Detection of a SARS-CoV-2 variant of concern in South Africa. Nature. 2021;592:438-43.

22. Faria NR, Mellan TA, Whittaker C, Claro IM, Candido DDS, Mishra S, Crispim MAE, Sales FCS, Hawryluk I, McCrone JT, Hulswit RJG, Franco LAM, Ramundo MS, de Jesus JG, Andrade PS, Coletti TM, Ferreira GM, Silva CAM, Manuli ER, Pereira RHM, Peixoto PS, Kraemer MUG, Gaburo N Jr, Camilo CDC, Hoeltgebaum H, Souza WM, Rocha EC, de Souza LM, de Pinho MC, Araujo LJT, Malta FSV, de Lima AB, Silva JDP, Zauli DAG, Ferreira ACS, Schnekenberg RP, Laydon DJ, Walker PGT, Schlüter HM, Dos Santos ALP, Vidal MS, Del Caro VS, Filho RMF, Dos Santos HM, Aguiar RS, Proença-Modena JL, Nelson B, Hay JA, Monod M, Miscouridou X, Coupland H, Sonabend R, Vollmer M, Gandy A, Prete CA Jr, Nascimento VH, Suchard MA, Bowden TA, Pond SLK, Wu CH, Ratmann O, Ferguson NM, Dye C, Loman NJ, Lemey P, Rambaut A, Fraiji NA, Carvalho MDPSS, Pybus OG, Flaxman S, Bhatt S, Sabino EC. Genomics and epidemiology of the P.1 SARS-CoV-2 lineage in Manaus, Brazil. Science. 2021;372(6544):815-21.

23. Zhang W, Davis BD, Chen SS, Sincuir Martinez JM, Plummer JT, Vail E. Emergence of a Novel SARS-CoV-2 Variant in Southern California. JAMA. 2021;325:1324-6. 